\title{
Study skills of children living in tsunami affected areas, Tamil Nadu, India
}

\begin{abstract}
Aim: To examine the study skills of children in tsunami affected areas of Tamil Nadu.

Methods: Study was cross-sectional in nature. Descriptive research design was used. 70 school children living in tsunami affected areas from Cuddalore, Tamil Nadu and Pondicherry were selected through purposive sampling method. School children aged from 8-16 years were participated. Study skills were assessed using study skill inventory and checklist.

Results: $54 \%$ were male and $46 \%$ were female children and their mean age was 13 years. $57 \%$ study 5 days in a week, $48.6 \%$ study $2-3$ hours in day, $57 \%$ study in the evening, $31 \%$ in morning hours, $12 \%$ study both in evening and morning time. $50 \%$ have poor time management skills, no time for social activities, poor concentration, $77 \%$ usually spend more hours in a night before an exam, $36 \%$ study with radio and TV tuned, $60 \%$ has difficulty in understanding their class notes, $52 \%$ have poor reading and retention skills, $40.5 \%$ had poor writing skills.

Conclusion: Most of the tsunami affected children have poor study skills in terms of difficulties in concentration, reading and retention, time management and no time for social activities. School-based psychosocial intervention programmes might be useful in addressing academic problems of tsunami affected children.
\end{abstract}

Volume 3 Issue 4 - 2017

\author{
Sinu Ezhumalai,' Samir Kumar Praharaj, ${ }^{2}$ \\ Ubahara Sahayaraj ${ }^{3}$ \\ 'Department of Psychiatric Social Work, National Institute of \\ Mental Health and Neurosciences, India \\ ${ }^{2}$ Department of Psychiatry, Kasturba Medical College, India \\ ${ }^{3}$ Cohort Manager, Center for Addiction Medicine, NIMHANS, \\ India
}

Correspondence: Sinu Ezhumalai, Department of Psychiatric Social Work, National Institute of Mental Health and

Neurosciences, India, Email esinu27@gmail.com

Received: May 09, 2017| Published: August 16, 2017

Keywords: study skills, tsunami affected children

\section{Introduction}

In December 2004, Tamil Nadu, massive underwater earthquake sent giant waves crashing into coastlines across Southern Asia. Children were hit hard by the tsunami. Families were left homeless and lost their livelihoods. Many children lost their parents or were separated from their families and their schools were destroyed. It is well recognized that the nature and extent of disaster can influence the psychological response of children. Acute traumatic events can produce disruptions in a child's social or living and learning situation that generally cause psychological damaging and leading to changes in the study environment. It is not surprising that children react differently to natural disasters. In this study, the authors were interested in investigating the study skills of school children with special reference to children living in tsunami affected areas after 18 months of tsunami disaster. Active rehabilitation was taking place with inter-sectorial collaboration from different Government, including Health, Education, Social Welfare and National and International organizations. Special attention was given to psychosocial care for children and disaster preparedness among them.

\section{Adjustment problems among children after natural disaster}

Chandrasekar et al. ${ }^{1}$ assessed the adjustment, self-esteem among children orphaned due to tsunami in Kanyakumari district, India. Adjustment in general and at school was found to be higher among the male children attending school. Adjustment in general and with peers was found to be higher among the 6-10 years. Orphaned children had significantly low self-esteem than the non-orphaned children. Priya et al. $^{2}$ reported that $75 \%$ of the tsunami affected children were having adjustment problems and other psycho-social issues, Nagai District, Tamil Nadu, and India. Few (14\%) children in Andaman and Nicobar islands have adjustment disorder and depression, $11 \%$ panic disorder and posttraumatic stress disorder, $2.7 \%$ schizophrenia and $43.2 \%$ other disorders during the first 3 months following the tsunami disaster. ${ }^{3}$

\section{Academic performance after natural disaster}

Teuku et al. ${ }^{4}$ reported that mean academic grade performance before tsunami was higher than after tsunami among college students which was not statistically significant. Loss of family member, House damage and loss of properties did not affect the academic performance of college students. There was no significant difference between survivors and non-survivors of tsunami in terms of academic performance. Martin et al. ${ }^{5}$ found that there was no statistically significant between victims and observers of tornado, 1979 regarding academic performance, grade, and school absence among $4^{\text {th }}$ and $5^{\text {th }}$ grade students for a period of four years. Brandon et al. ${ }^{6}$ stated that there was a negative association between aggression and academic achievement among $4^{\text {th }}-8^{\text {th }}$ grade school children who were victims of Hurricane Katrina.

\section{Intervention studies on children affected in tsunami}

As there were limited studies on study skills of children in general and children living in tsunami affected areas therefore overview of studies on children affected in tsunami were given in this article. Post-disaster intervention studies in children are few in developing countries. 
NIMHANS ${ }^{7}$ provided psychosocial care for children in tsunami affected areas using different mediums such as painting, thematic cards, clay, family dolls through tailor made psychosocial care training to various stakeholders in Tamil Nadu and Puducherry (community level workers, non-government organizations, school teachers, volunteers, schools of social work). Most post-disaster psychosocial interventions were provided in the community by community level workers in group mode. ${ }^{8}$ Supportive counselling, debriefing, psychosocial care through mediums and play therapy were the commonly utilized methods of psychosocial intervention.

An intervention programme for children was developed and given to 65 children in six intervention modules and compared to 70 children at Srinivasapuram, Chennai, and one year after tsunami. Post-assessment revealed significant reduction in hyperactivity in the intervention group and were more likely to abstain from smoking compared to control group. Children with pre-existing vulnerability require specific and specialized interventions after disaster. ${ }^{9}$ Targeted specialized mental health services are needed for children with severe exposure to the tsunami and positive family history of psychopathology. ${ }^{10}$

\section{Psychiatric morbidity}

Common psychiatric manifestations among children include acute stress reactions, adjustment disorder, depression, panic disorder, posttraumatic stress disorder, anxiety disorders specific to childhood and psychotic disorders. Co-morbidities and sub-clinical syndromes were also common. ${ }^{11}$ Prevalence of PTSD in tsunami affected students of Takuapa District, Thailand showed decreasing trend from $46 \%$ to $3 \%$ from 6 months to 5 year follow-up interval period. ${ }^{12-14} \mathrm{Few}$ children (15\%) had either depressive disorder or anxiety disorder $25 \%$ of students completely recovered from mental disorders and nearly $50 \%$ of students were in partial remission or sub-clinical PTSD after 3 years of tsunami. Factors which influenced long-term outcomes were prior history of trauma and severe physical injury from the disaster. ${ }^{15}$

\section{Need for the study}

Academic achievements and expectations itself are demanding for the children, when they are in phase of adolescence is turmoil and exposure to catastrophic event such as tsunami disaster places devastating impact on their psycho-social well-being. Most of the mental health studies focused on psychiatric manifestations in children after the tsunami. After health needs, academic needs are given more importance for school children. During tsunami many people in coastal areas have lost their livelihood, houses, and family members. In this context, an attempt was made to study the study environment and study skills of children living in tsunami affected areas. The aim was to investigate the study skills and environment of children living in tsunami affected areas.

\section{Methods}

This was a descriptive study carried out in tsunami affected areas of Cuddalore, Tamil Nadu and Puducherry, in Southern India. Sample comprised of 70 school children aged 8-16 years, selected through purposive sampling technique. 35 children were selected from Cuddalore district and another 35 children selected from Union territory of Puducherry. Interview schedule was used to obtain the data from the participants during the home visits by the first author (SE). Data was collected over a period of two months from May to June 2006. As there were no Institutional Ethics Committee review board during 2006 in Tsunami affected areas, hence Informed consent was taken from the parents of the participants. Socio-demographic details were collected using a pro-forma designed for the study. A 17-item self-administered Study Skills Checklist, ${ }^{16}$ modified from the original 21 -item questionnaire was used to find out study habits and attitudes. It has seven domains including time scheduling, concentration, listening and notes taking, reading, writing, and testing and exams. Each item has 'yes' or 'no' dichotomous response. Higher scores indicate poor study skills.

\section{Results}

Sample characteristics are summarized in Table 1. In this study, more than half $(54 \%)$ of the participants were boys and $46 \%$ were girls. The age of children ranged from 8 to 16 years. Of these children, more than half $(57 \%)$ of them study five days in a week, and onefourth of them study almost every day. Almost half (48.6\%) of the children study two to three hours per day, 33\% study more than four hours in a day, and $18 \%$ study for one hour and less than one hour. 57 $\%$ preferred to study in the evening, $31 \%$ study in the early morning and only $12 \%$ preferred to study both in evening and morning time. Table 2 illustrates the study skills of children.

Table I Study skills related information $(\mathrm{N}=70)$.

\begin{tabular}{llll}
\hline Study variables & & $\begin{array}{l}\text { Boys, } \mathbf{N}=\mathbf{3 8} \\
\mathbf{n}(\%)\end{array}$ & $\begin{array}{l}\text { Girls, } \mathbf{N}=\mathbf{3 2} \\
\mathbf{n}(\%)\end{array}$ \\
\hline & $<I$ & $2(5.26)$ & $\mathrm{I}(3.10)$ \\
Study duration (in hours) & $\mathrm{I}-2$ & $3(7.89)$ & $7(21.80)$ \\
& $2-3$ & $1 \mathrm{I}(28.94)$ & $9(28.12)$ \\
Number of study days in a week & $3-4$ & $10(26.30)$ & $4(12.50)$ \\
& $>4$ & $12(31.57)$ & $\mathrm{II}(34.37)$ \\
& Less than 4 & $7(18.42)$ & $4(12.50)$ \\
Study timing & $4-5$ & $21(55.26)$ & $19(59.37)$ \\
& $6-7$ days & $10(26.30)$ & $9(28.12)$ \\
& Early morning & $14(36.84)$ & $8(25.00)$ \\
& Evening & $20(52.63)$ & $20(62.50)$ \\
& Both & $4(10.52)$ & $4(12.25)$ \\
\hline
\end{tabular}


Table 2 Study skills of tsunami affected children $(\mathrm{N}=70)$

\begin{tabular}{|c|c|c|c|}
\hline & Study Skills & $\mathbf{n}$ & $\%$ \\
\hline & Time Scheduling & & \\
\hline 1 & I spend too much time studying for what I am learning & 46 & 65.71 \\
\hline 2 & I usually spend hours cramming the night before an exam. & 54 & 77.14 \\
\hline 3 & If I spend as much time on my social activities as I want to, I don't have enough time left to study & 41 & 58.57 \\
\hline \multirow[t]{2}{*}{4} & When I study enough, I don't have time for a social life. & 35 & 50.00 \\
\hline & Concentration & & \\
\hline 5 & I usually try to study with the radio and TV turned on. & 25 & 35.71 \\
\hline 6 & I can't sit and study for long periods of time without becoming tired or distracted. & 38 & 54.28 \\
\hline \multirow[t]{2}{*}{7} & I go to class, but I usually doodle, daydream, or fall asleep. & 33 & 47.14 \\
\hline & Listening and Notes taking & & \\
\hline 8 & My class notes are sometimes difficult to understand later. & 28 & 40.00 \\
\hline \multirow[t]{2}{*}{9} & I usually seem to get the wrong material into my class notes. & 29 & 41.42 \\
\hline & Reading and Retention & & \\
\hline 10 & When I get to the end of a chapter, I can't remember what l've just read. & 32 & 45.71 \\
\hline II & I don't know how to pick out what is important in the text. & 40 & 57.14 \\
\hline \multirow[t]{2}{*}{12} & I can't keep up with my reading assignments, and then I have to cram the night before a test. & 28 & 40.00 \\
\hline & Testing and Exams & & \\
\hline 13 & I lose a lot of points on essay tests even when I know the material well. & 37 & 52.85 \\
\hline 14 & I study enough for my test, but when I get there my mind goes blank. & 29 & 41.42 \\
\hline \multirow[t]{2}{*}{15} & I often wish that I could read faster. & 55 & 78.57 \\
\hline & Writing skills & & \\
\hline 16 & When my teachers give homework, I feel so overwhelmed that I can't get started. & 26 & 37.14 \\
\hline 17 & I usually write my homework the night before they are due. & 31 & 44.28 \\
\hline
\end{tabular}

\section{Discussion}

In this study, half of the children talk to others when they study. Almost half $(46 \%)$ of them spend too much of their time for what they learn and $41 \%$ do not get enough time to study due to their living condition. More than half (54\%) of them reported that they study hardly one day before the exam. These children have poor time management skills in the study aspects. Half of them do not get time to spend on social activities. Half of the children couldn't sit and study for long hours, and they get tired very easily. One third of them tune on radio and watch television while they study. Almost half of them sleep and daydream during their class hours. The studies revealed that significant proportion of children have poor concentration. Also, $40 \%$ of children have poor listening and notes taking skills. Half of them have difficulty in understanding the main theme and remembering what they read. In the present study a significant number of students have inadequate reading and retention skills. This finding was in concordance with previous study. ${ }^{17}$ Adolescent children had poor reading, retention skills before life skill education. life skills education improved study skills scores significantly among high school students. Study skills such as exam preparation and time management tend to improve after life skill education. Life skill training could not improve concentration skill. Reading and memory was associated with improvement in life skill of coping with stress. There was an association between study skill variables such as reading and memory, exam preparation and time management. Concentration and exam preparation were positively correlated. However, study skills did not differ significantly among adolescents in terms of birth order, religion, family type, father's occupation and family annual income.

There is need for reform in present education system shifting the focus from academic skill (marks oriented) to life-skill oriented. ${ }^{18}$ As majority did not have time for social activities, it will be prudent to reduce the length of school hours as children need to grow in all dimensions, including physical, psychological, social and spiritual. Education is one of the developmental task and not the only task they should master. Due importance need to be given to physical education, yoga and music in the syllabus and it should become part of living. One way this can be achieved is to reduce the lesson load. Lessons in all the subjects should be integrated to their everyday life to facilitate practical applications of the syllabus. Understanding other people emotions, communicating effectively, skill in solving the interpersonal problem, skill in converting threats and challenges into opportunities are more important than understanding mundane theories. ${ }^{19}$

Limitations of the study include cross-sectional design and lack of a comparison group. The study did not compare the study skills between gender, across different age group, and other socio- 
demographic variables. Also, the tool used in this study not validated in Indian populations. Furthermore, presence of psychiatric morbidity was not assessed in the present study. While present study showed poor study skills among children living in tsunami affected areas, however it is difficult to determine if the skills demonstrated by the children in this study differ significantly from that of comparable children who were not affected by the tsunami and of the same culture. The study would have been better if the study had collected data on academic performance to compare the study skills with academic performance.

\section{Conclusion}

Most of the tsunami affected children have poor study skills in terms of difficulties in concentration, reading and retention, time management and no time for social activities. School-based psychosocial intervention programmes might be useful in addressing academic problems of tsunami affected children.

\section{Acknowledgements}

None.

\section{Conflicts of interest/Funding}

The authors declare no conflicts of interest.

\section{References}

1. Chandrasekar P, Sekar K Self-esteem, adjustment and impact among children orphaned in tsunami. Department of psychiatric social work, India: NIMHANS.

2. Priya R, Kanaga G. A study on status of tsunami affected children in Nagai District of Tamil Nadu. International Journal of Scientific and Research Publications. 2013;3(6):1-5.

3. Math, Shweta Tandon, Satish Chandra Girimaji, et al. Psychological impact of the tsunami on children and adolescents from the andaman and nicobar islands. Prim Care Companion J Clin Psychiatry. 2008;10(1):3137.

4. Teuku Tahlil, Ches Jones. The 2004 tsunami and university students' academic achievement. The Australasian Journal of Disaster and Trauma Studies. USA: Springer; 2008.

5. Martin Sander, Little Brenda. The effects of a natural disaster on academic abilities and social behaviour of school children. Journal of Special Education. 1986;10(2):167-182.
6. Brandon G Scot, Genevieve E Lapré, Monica A Marsee, et al. Aggressive behavior and its associations with posttraumatic stress and academic achievement following a natural disaster. J Clin Child Adolesc Psychol. 2014;43(1):43-50.

7. E Sinu, K Sekar, R Dhanasekarapandian. A297) Psychosocial Care for Children Survivors of Tsunami Disaster - Pondicherry Response, India. Prehospital and Disaster Medicine. 2011;26(S1):s83-83.

8. Prabhu T, Sinu E. Psycho-social Care for Children in Disaster. Journal of School Social Work. 2006. p. 11-18.

9. Vijayakumar L, Kannan GK, Ganesh Kumar B, et al. Do all children need intervention after exposure to tsunami. Int Rev Psychiatry. 2006;18(6):515-522.

10. Vijayakumar L, Kannan GK, Daniel SJ. Mental health status in children exposed to tsunami. Int Rev Psychiatry. 2006;18(6):507-513.

11. Kar N. Psychological impact of disasters on children: review of assessment and interventions. World J Pediatr. 2009;5(1):5-11.

12. Piyasil V, Ketumarn P, Prubrukarn R, et al. Psychiatric disorders in children at one year after the tsunami disaster in Thailand. J Med Assoc Thai. 2008;91(Suppl 3):S15-20.

13. Piyasil, Ketuman P, Plubrukarn R, et al. Post-traumatic stress disorder in children after tsunami disaster in Thailand: 2 years follow-up. $J$ Med Assoc Thai. 2007;90(11):2370-2376.

14. Piyasil V, Ketumarn P, Prubrukarn R, et al. Post-traumatic stress disorder in children after the tsunami disaster in Thailand: a 5-year follow-up. $J$ Med Assoc Thai. 2011;94(Suppl 3):S138-144.

15. Ularntinon S, Piyasil V, Ketumarn P, et al. Assessment of psychopathological consequences in children at 3 years after tsunami disaster. $J$ Med Assoc Thai. 2008;91(Suppl 3):S69-75.

16. Study Skills Checklist. Cook Counselling Center.

17. Divya Ravindran, Parthasarathy R. Influence of life skills education on skills of coping with stress of high school students. National Journal of Professional Social Work. 2013;14(1-2):49-58.

18. Srikala B, Kishore KK. Empowering adolescents with life skills education in schools -School mental health program: does it work. Indian $J$ Psychiatry. 2010;52(4):344-349.

19. Sekar K, Prabhu, Kavitha P, et al. Manual on Intervention with Children Affected by Tsunami Using Psychosocial Care Medium, NIMHANS Every Child India; 2007. 